\title{
Toward a Pedagogy for Professional Noticing: Learning through Observation
}

\author{
Donna Rooney ${ }^{1}$ (I) $\cdot$ David Boud ${ }^{1,2}$
}

Received: 12 April 2018 / Accepted: 29 April 2019 / Published online: 17 May 2019

(C) The Author(s) 2019

\begin{abstract}
A necessary skill that underpins all professional practice is noticing that which is salient. Noticing can be learned directly and indirectly through a variety of campusbased and placement activities. This paper suggests that developing a capacity for noticing is under conceptualised and underdeveloped in courses preparing students for the professions. It discusses three aspects of noticing: noticing in context, noticing of significance and noticing learning, and explores the use of these through a case study of simulation in nursing education. The case study points to the importance of close attention to the circumstances in which noticing can be fostered and, in doing so, points toward the potential of developing a pedagogy of professional noticing.
\end{abstract}

Keywords Noticing · Observers · Preparation for practice · Work-integrated learning · Simulation

\section{Introduction}

One of the key functions of higher education is to prepare students for professional practice. This is a complex process which involves a wide range of activities in addition to the acquisition of knowledge and skills (Bates and O'Brien 2013, p.619). Students must learn their practice as well as how to perform their practice, in context, with other people and with material things (Fenwick et al. 2011) - a process more sophisticated than the oft quoted phrase 'turning theory into practice' implies.

Experienced professionals, regardless of their field of practice, have in common a capacity to 'read' the practice domain along with a capacity for informed decision making within it. Underpinning these capacities is the notion of noticing, which often

Donna Rooney

donna.rooney@uts.edu.au

1 University of Technology Sydney, Ultimo, Australia

2 Deakin University, Geelong, Australia 
manifests in various kinds of observing activities for difference purposes. For instance, experienced nurses observe their patients and notice changes to which they must respond (Tanner 2006; Watson and Rebair 2014). Likewise, experienced teachers observe their students and notice what is happening in order that they can appropriately intervene when necessary (Barnhart and van Es 2015; Stürmer et al. 2015).

We suggest that pedagogical attention to professional noticing may contribute to novice's accomplishment of this key challenge. The purpose of this paper is to illuminate potential areas of pedagogy that have untapped potential for helping preservice professionals develop what Goodwin (1994) describes a professional vision, or what Borich (2016) calls a professional frame, and what we instantiate in noticing here. We see developing capacity for noticing as central to developing expertise for practice and argue that noticing is an under conceptualised aspect of pre-service education to which attention needs to be addressed if explicit pedagogies of noticing are to be effectively developed.

While there is some discussion of noticing in discipline-specific literatures, we propose that it needs to be located as a central concern of higher education more generally given the increased emphasis on students gaining experience of practice through work-integrated learning in courses for which this was not previously expected (Cooper et al. 2010; Higgs et al. 2012). Without a well-developed capacity for noticing, students may not make an effective transition into practice, nor operate successfully within the world of practice.

The specific aim of this paper is to establish the rationale for the development of an explicit pedagogy of noticing. It acknowledges the existence of some profession-related pedagogies that focus on observing, discussed in discipline-specific journals, and seek to position noticing and observing in the wider higher education literature. We also note that noticing itself is generally an implied feature in observation and is often treated as non-problematic. Thus, we seek to make noticing explicit and worthy of consideration. To do this we use a case study to illustrate how a course-based pedagogy can help preservice students develop a capacity for noticing that they can subsequently take into the workplace.

\section{Why Noticing?}

We use this term, firstly, because of the currency it holds in several areas of professional scholarship. For instance, in nursing literature the term is widely referred to as an important first step in accepted models of clinical judgement (Tanner 2006; Watson and Rebair 2014; Lasater 2007). In education literature, and mathematics education in particular, experienced teachers are said to observe their students and notice what is happening in order that they can appropriately intervene when necessary (Barnhart and van Es 2015; Stürmer et al. 2015; Mason 1993, 2002). In business, Bazerman (2014) advocates for business leaders to systematically read contexts and notice salient features that might then be used to predict events and plan contingencies. In a similar vein project managers' risk management strategizing is premised on their capacity to notice (Kutsch and Hall 2016). In all, noticing is seen as critical in many professional domains - no doubt because failure to notice salient aspects or significant behaviours can lead to poor outcomes, and in some professions, catastrophic repercussions (Dossey 2008; Watson and Rebair 2014). 
Given our interest in pre-service education, a second justification for using the term is its links to professional learning. For instance, Mason links noticing to learning, in what he calls professional noticing. He explains this as:

[W] hat we do when we watch someone else acting professionally (teaching a lesson, working with a client, leading a workshop, delivering a lecture or training session) and become aware of something that they do (a task they set, a pattern of speech they employ, a gesture they use, a question they ask) which we think we could use ourselves (Mason 2002 p.30).

For Mason (1993, 2002), observing others performing professional practice, and noticing particular features, can lead to new learning. This is not to say learning occurs every time episodes of professional practice are observed. To be open for learning potential Billett (2016) argues there must be some intent to learn from observing practice. Boud and Walker (1990) made a similar point in earlier discussions of experience-based learning, where describing how features of experiences must first be noticed before they can be reflected on.

Noticing, then, is both an intentional activity that can be learned (Goodwin 1994; Borich 2016; Bazerman 2014; Tanner 2006; Mason 2002) as well as an activity that promotes learning in itself (Billett 2016; Boud and Walker 1990; Mason 1993, 2002). Despite differences in proximity to action for those observing professional practice and those performing professional practice, noticing is embedded in both.

\section{Developing Noticing}

Preparing for professional practice of any kind involves not only learning the knowledge germane to the practice domain, but also developing a professional vision (Goodwin 1994). That is, a way of "seeing and understanding events that are answerable to the distinctive interests of a particular social group" (p.606). Others call this a professional frame which Borich (2016) describes as the capacity to continually 'read' the unfolding action in the specific professional context (p.9). Despite differences in nomenclature, Goodwin (1994) and Borich (2016) draw attention to how professionals have capacity to make sense of what they observe in their everyday practice and use their understanding of what is being observed to make informed decisions about how to act within it.

While cognitive activity is involved (explicitly for Goodwin, less so for Borich), the human sensory function of seeing provides an initial starting point. However, for Goodwin and Borich, as well as for us, it is a nuanced form of seeing that is at stake. Mason (2002, after Bateson 1994) illustrates this when he describes noticing as - "being awake to situations, being mindful rather than mindless" (p.38).

But how do pre-service professionals establish an initial professional vision/frame? One, perhaps obvious, response to this may be through placements or internships, where students rehearse 'reading' the complexities of the practice domain first hand. Along with others, we suggest that the foundation for this occurs not in the placement itself, but in the teaching and learning activities prior to and following observation. Goodwin (1994), drawing examples from archaeology and law, illustrates how novices 
develop their professional vision through the practices of coding; highlighting; and articulating material representations. In Goodwin's terms, Borich (2016) also advocates for highlighting aspects of practice through a range of focused observation activities in order that they become practically intelligible for novice teachers. While learning is implied, the concept of noticing enables us to make it even more prominent.

Learning through noticing involves the learner in constructing their own conceptions of appropriate practice through an understanding of the knowledge domain on which their professional practice is based, on their own observations of practice and on their making sense of these within a social context or community of practice. Before exploring how noticing might be developed, it is useful to distinguish various aspects of noticing. We do this by first considering noticing of experienced practitioners in the professional domain, which differentiates two forms of noticing before turning to noticing in preservice professional education which invites a third form.

\section{Noticing in the Professional Domain}

Experienced professionals must not only understand the propositional and procedural knowledges accepted within their domain but must also recognise and enact these in everyday practice. Depending on what is noticed, they make judgements about if, and when, interventions are necessary, as well as decide what those interventions might be. Routine interventions (i.e. if ' $A$ ' then ' $B$ ') may be common, but this requires professionals to notice significant features of practice in the first place. This suggests at least two forms of noticing are required of professionals.

The first form of noticing is noticing in context. It is about noticing the scope of practices that constitute a professional domain, and how these are bound together and when/how they manifest in the messiness of everyday professional contexts. This is more than discerning the knowledge features of an isolated practice purged from the professional context in which it occurs, but how multiple practices simultaneously happen in authentic situations. Over time, professionals develop a 'professional frame' that enables them to fluently read unfolding and complex episodes of practice and how to act in them (Borich 2016 p. 9). Lasater (2007) identifies multiple dimensions of noticing and positions these along a continuum from beginng through to exemplary. For her, beginning noticing involves 'focused observation' but typically on 'one thing at a time', whereas, 'exemplary' noticing involves 'monitoring from a wider position that recognizes subtle patterns and deviations from expected patterns in data' (2007 p.500).

This leads us to a second form of noticing, noticing of significance. In the messiness of everyday activity professionals also meet situations where routine interventions are not viable or appropriate. Professionals also need to be able to readily identify what they should be attending to and what they should do if there is any deviation from what is expected. Rose calls this 'disciplined perception' (2014 p.73): to notice aspects of practice in order that it becomes available for them to act on. This noticing builds on but moves beyond, simple noticing in context. It is noticing of significance and judging in action what to do about the unexpected. Goodwin (1994) alludes to this when discussing how of the police officers coded Rodney King's behaviour as aggressive which justified their subsequent actions. Experienced professionals notice significant deviations from the anticipated flow of events and will initiate responses confidently 
and without delay. This is also what Mason identifies as marking: 'a heightened form of noticing' (Mason 2002, p. 33). The ability to mark is a sign of expertise and, although a well-developed capacity for this may be beyond reasonable expectations for novice practitioners, its development may be seeded in professional education programs.

\section{Noticing in Professional Education}

Obviously, learners need to learn the fundamental concepts of the professional domain they are entering (Land et al. 2016). At the most basic level, they need to notice salient aspects of the phenomena they are learning about and distinguish these from others. When learning about a topic in a classroom, student-nurses would need to realise that blood pressure, for example, is an important indicator to consider in nursing care and to differentiate it and relate it to other phenomena they are learning about (e.g. Bowden and Marton 1998). While this form of 'cognitive noticing' is a basic feature of any learning it is not our primary focus here.

However, professional contexts are rarely, if ever, as controlled as the ones in which students learn about their profession. Capacity to notice within the knowledge domain does not mean that learners are able to perform knowing in a practice setting. Students must also learn to 'read' the professional contexts that they are entering (Barnes and Solomon 2014). Like their more experienced counterparts, they need to understand how the various practices that constitute the profession 'hang together' and recognise these within a practice setting. In other words, students need to develop a capacity for noticing in context.

However, capacity to 'read' an unfolding episode of practice in professional setting is not enough - in order to act students must also make decisions about how to act and what to attend to. It is here that noticing of significance is necessary. This is the not only the case in making routine judgements about course of action (if A then B) but also when making informed judgements in non-routine situations (and knowing the difference). Students may flounder when initially faced with the situations that their more experienced counterparts confront on a daily basis, and in doing so overlook (not notice) features that need their attention. They need to develop a capacity for noticing the salient features of what they observe.

Finally, in addition to the two forms of noticing above we need to recognise a necessary third form of noticing: noticing learning itself. In educational contexts, there is much noticing required of students. Learners need to notice what is needed of them, they need to utilise important information and direct their own learning activities in the direction required by a clear understanding of the circumstances they find themselves in, and where they wish to end up. Self-direction and self-regulation are initiated by noticing or are preceded by it. This is also what Boud and Walker (1990) describe as noticing in their discussion of reflection in learning from complex educational experiences. It involves a cycle of noticing, intervening, reflection on the outcome, leading to further noticing, intervention and reflection. This is somewhat akin to Schön's (1983) notion of learning from reflective practice and comes from the tradition of experiential learning. Noticing can thus been seen as a component of reflection. However, the reflection literature tells us little about the noticing or observing phases of learning cycles. For learning to be assured, however, students must approach a situation with an intent to learn which is a powerful shaping influence on what they attend to (Boud and 
Walker 1990). We add that while noticing learning commonly begins as part of preservice education, it is just as important for experienced professionals in responding to their needs for continual learning.

\section{Placement Activities that Develop Professional Noticing}

Opportunities to develop noticing can be seen in disciplines that include placements tightly coupled to coursework, such as in pre-service education in social work, teaching and nursing. A pedagogy of noticing can be seen when students are prepared beforehand about what to notice and they engage in activities to make sense of what they have observed (Borich 2016). Pre-service teachers at our own institution, for example, are provided 'practicum booklets' that guide them in their observations of experienced teachers' practices and classrooms. Many of the prompts in these booklets embody Borich's (2016) lenses: from noticing the general learning climate of classrooms and how student behaviours are managed through to how students are oriented toward tasks. Such placements provide students with opportunities to develop capacity for noticing in context as well as hold potential to notice moments of significance where students can predict (and in some cases, respond to) subsequent action. Well-designed protocols, briefings and professional supervision sessions may also work to enhance the development of noticing learning.

Other placement activities also provide a range of opportunities for students to be immersed in authentic professional settings (Lucas and Leng Tan 2014), although these are often more loosely coupled to coursework than those above: e.g. internships, fieldwork, cooperative education, sandwich courses and service learning (Cooper et al. 2010, pp. 38-39). These may also develop capacity for noticing in context as well as noticing of significance, and because these activities commonly include the use of reflective journals, this can aid noticing for learning. However, in some courses, where the work-related element may be less tightly linked to the learning outcomes of the course and wide variation of types of experience is accepted, then explicit activities scheduled to promote noticing are often absent.

\section{Preparing for Placement}

Pre-placement aspects of courses can provide opportunities for developing noticing. Examples of this include case studies, observations and simulations. Case studies, like those used in business or law vary in richness and can present textual accounts of professional practice requiring students to notice features. However, case studies that are text-based or which provide no more than a general briefing of a situation, do not readily lend themselves to noticing beyond the cognitive. Decontextualised or abstracted cases provide little opportunity for the kinds of notice we are concerned with here.

Observations, where students observe experienced professionals engaged in authentic practice, either in situ or captured through video representations, also provide opportunities for noticing. Sometimes facilitators give verbal instructions and/or observation guides (sometimes called observation forms, rubrics or other names). Both of these facilitators' interventions help students to notice specific or salient features (Torres et al. 2017; Amador 2017; Smyth 2011). 
Simulation is another activity that can develop noticing. It is increasingly used in diverse areas of higher education (e.g. law, political science, the sciences and health) and provides students with opportunities to be exposed to aspects of practice through simulated encounters. Also, as opportunities diminish for undergraduates to secure suitable external placements and supervision, simulation has become more widely used because it can act as an 'intermediate practice' (Boud and Rooney 2015, Rooney et al. 2015), that is, one which provides a link between abstracted practices represented in traditional coursework and the full immersion of a placement. Its increased use explains a corresponding increased research base especially in health-related professional education.

Simulation provides a helpful vehicle for this paper because it involves observation in a context which is relatively controlled (compared to a placement) and where what is noticed can potentially be immediately applied. Moreover, while it is conventionally assumed that simulation necessarily involves students taking active roles, as student numbers increase even these opportunities for participation are becoming limited, leading to an increase in the number of students observing their peers perform simulated practice. We utilise a case study of simulation here because it illustrates the potential for a pedagogy of noticing both through observing and performing, as well as how various forms of noticing can be introduced with relatively large numbers of students. The case study also draws attention to missed opportunities where noticing skills might be further developed.

\section{Case Study of Noticing in Simulation Classes}

\section{Background}

Our illustration of noticing draws on a body of observations and analysis undertaken in a nursing simulation laboratory in a large metropolitan Australian university over a period of three years. While the broader study was conducted to explore issues of pedagogy in simulation (Boud and Rooney 2015, Hopwood et. al 2014), we use features of the data collected to ground our discussion of noticing in the context of professional education rather than in simulation per se.

A team, consisting of both education and nursing researchers, observed 18 simulation events in a course unit called 'critical care': a final year subject for undergraduate nurses running $2 \mathrm{~h}$ a week for 14 weeks. The subject deployed simulation activities toward the end of semester. Students were provided with a case scenario and other materials to prepare them prior to the session. Around 25-30 students were enrolled in each class and each scenario had between four and six acting roles (e.g. handover nurse, nurse, team-leader and/or patient relative). This meant students took turns in acting roles while the remaining students observe. Over the semester not all students had the chance to act - but all students had multiple opportunities to observe.

Classes involved observers and actors co-located in a simulation lab, separated by a mobile partition. On one side of the partition was furniture found in a typical classroom. On the other side was a hospital bed surrounded by monitors and equipment that one might expect to find in a hospital. Cameras record bedside action and provide a live feed to the screen where the observers sat.

In addition to the material context of the simulation (e.g. beds, medical equipment, charts, phones) an important aspect of the context were the 'patients' 
themselves. The various 'patients' (high-tech manikins) in each scenario were more than a medical condition. Each had been given an identity (age, gender, etc.), a medical history as well as a backstory. Most 'patients' had at least a relative or friend with them as well (who also had backstories). These identities and backstories were revealed as the scenario unfolded. Scenario 1 involved a patient (the manikin), accompanied in the emergency department by his (anxious) wife (played by a student). Scenario 2 involved a younger patient (manikin) accompanied by his girlfriend (played by a student). His backstory included the recent use of illicit drugs and some hesitancy by both the patient and girlfriend to reveal this information. Both scenarios were designed in such a way that a critical medical incident would ensue. In Scenario 1 the patient goes into cardiac arrest, and in Scenario 2 the patient has an asthma attack and subsequent reaction to the medication administered. Observation guides for simulation observers were made available to students prior to class.

Toward the end of the research an unanticipated opportunity arose enabling us to extend our study. Having identified that there was room to improve the experience of being an observer in the simulation classroom, we then focused our attention on simulation observers. We made changes to how student observers were organised including arranging them into small groups that each focused on a different aspect of the simulation. The results of this are described more fully elsewhere (Kelly et. al 2016; Rooney and Kelly 2019). But in short, our interventions involved shifting the logic of the prompting questions from evaluating (i.e. What did their acting peers (not) do well?) to a small number of related questions presented in tabular form to prompt observers to notice the relationships in what they were noticing. The redeveloped observer guides were piloted in further four simulation cycles. Identical data collection processes to those used in the original research enable us to comment on the outcomes of these developments.

\section{Noticing in Context}

Students in acting roles practiced noticing in context, as well as supporting each other to notice. In this first example (Scenario 1), the patient arrives in 'emergency' where the attending student nurses begin following the procedures they have learned. The patient is complaining about pain, the wife is panicking, monitors are beeping and there has just been a decision made to give the patient morphine (which one nurse prepares). However, another nurse fails to follow procedure, so another reminds her:

Nurse 1: We need to check the obs.

Nurse 2: Yeah, we can check his obs.

A facilitator played the role of a doctor in each scenario. This dual role involved facilitating learning and administering medical care. For instance, during the scenario the facilitator/doctor uses direct questioning: 'Excuse me, nurse - how was his air entry when you listened to him?' Such questioning can be understood as 'what did you notice?' She also prompts student noticing when action is through her commands: 'Maybe you want to check his circulation' -here she prompts the student-nurses to notice (in this case the patient's circulation). 
Another way the dual role of facilitator/doctor manifest was when they "notice aloud':

So, he's got bruising on the left side of his chest, and in there, and he's got burns to his right arm.

Okay, so his saturation is now 96. His heart rate's a little bit fast.

Even while the bruising, burns, saturation levels and heart rates are in full view of the acting students, they might not necessarily notice these in the complexity of the simulated context. This noticing aloud guides students (acting students, in particular) to take note of features of the context (and unfolding action). Meanwhile, observing students (who cannot see the bruises, injuries etc.) can also hear the facilitator/doctor and thus may also be prompted to notice. It is difficult to know for sure if observing students were noticing in context while the actual simulation was underway. However, in the debriefing sessions some observers' comments suggested that some noticing was occurring. For example, there were comments that relayed the unfolding situation from the handover, to the initial assessment to the patient deterioration which suggests that the students were reading the context from watching the video screen in front of them. When asked what their peers did (or did not) do well observers often noticed when the action did not unfold in ways they assumed 'good practice' should. For instance, an observing student commented that he noticed procedures were not followed. Another observing student noticed that the acting nurses did not use gloves. To which the acting student in question responded by saying 'I actually tried to find some gloves, but I was so panicked'. Here we see the student who appears to know 'in theory' that he should have been wearing gloves, but also admits to being panicked (i.e. not noticing in context) - yet the observer was able to notice the absence of gloves without the added stress of being embedded in the action.

In the later cycles of simulation observed in our research, where the redeveloped observer guides were used, we also identified observers noticing relationships between various activities they observed. For example, the guide for students responsible for observing clinical actions noticed the following in Table 1:

This illustrates how the observers were prompted to notice [the delivering a nebulizer] in context as well as noticing the significance of low oxygen saturation in a temporal sequence that links the occurrence of 'low oxygen' with the 'delivering

Table 1 Example of redesigned observer guide questions and student responses

\begin{tabular}{|c|c|c|c|}
\hline $\begin{array}{l}\text { A. What are the } \\
\text { clinical actions? }\end{array}$ & $\begin{array}{l}\text { B. How do these actions } \\
\text { come about, and who } \\
\text { instigates them? }\end{array}$ & $\begin{array}{l}\text { C. Does the action } \\
\text { happen at the most } \\
\text { appropriate time? } \\
\text { Would it have been } \\
\text { better at a different } \\
\text { time? }\end{array}$ & $\begin{array}{l}\text { D. What does this tell you } \\
\text { about key ideas or } \\
\text { concepts you already } \\
\text { know about? What are } \\
\text { the implications for } \\
\text { your practice? }\end{array}$ \\
\hline Delivered Neb[ulizer] & $\begin{array}{l}\text { Measurement shows } \\
\text { patient has low } \\
\text { Sat[uration] }\end{array}$ & $\begin{array}{l}\text { RN1 decides to deliver } \\
\text { nebulizer }\end{array}$ & $\begin{array}{l}\text { Give immediate response } \\
\text { to patient's complaints } \\
\text {.. building a good } \\
\text { relationship between } \\
\text { patient and nurses. }\end{array}$ \\
\hline
\end{tabular}


nebulizer'. Another example, where observers were responsible for shadowing the team leader (TL), the observer guide asked: "When does the TL step back from the action? What effect does this have?" To which, an observer group response was:

The TL steps back when the TL calls the RMO for a drug order. When the TL steps back there was a bit of confusion.

Once again, we see students noticing in context: where 'confusion' and the 'team leader withdrawing' have temporal links within the unfolding practice. Rather than noticing isolated activities, they are noticing activities in an unfolding context. Furthermore, these rich examples of observers' noticing, via asking different sorts of questions, illustrates a shift toward exemplary noticing - consistent with Lasater's definitions (Lasater 2007 p.500).

\section{Noticing of Significance}

In Scenario 1 a drop in blood pressure is designed to precede the patient's cardiac arrest. This constituted a moment of significance for the acting students who generally (although not always) notice this without any prompting:

Nurse 2: His blood pressure is low.

Nurse 1: It's very low.

Nurse 2: 88/68. Should we call for medical review or...

Nurse 1: Yes, so maybe you can just call the doctor.

Not only do these students notice the significance of the fall in blood pressure but they also collectively consider, and then enact, an appropriate response (even if hesitantly). In most of the cycles where this scenario was used CPR (the appropriate action) followed the onset of arrest with little prompting. This suggests acting students noticed something of significance and made the correct clinical judgement: 'if A then B'. On a few occasions when acting students failed to notice or consider possibility of cardiac arrest the facilitator prompts them by noticing aloud and/or narrating the patient's deterioration.

In the other part of the classroom, the monitor on the screen also shows the drop in blood pressure. Over the majority of simulations observed, we saw a few observers point to the screen and/or whisper to one another at this moment- suggesting that some has also noticed the significance of this. Most observers, however, did not react to the event - although the drama of their peers administering CPR generally captured their attention.

On the other hand, in Scenario 2, observing students not only notice the significance of the situation unfolding, but also appear to be quicker to predict what was happening than their acting peers. The scenario depicts a patient's adverse reaction to administered medication brought about by illicit drug use. This situation required students to consider possibilities beyond what they had learned in class. While acting students immersed in the scenario appeared to skirt over the 'clues', observers pointed to the screen and engaged in small group discussions indicated that they had made the illicit drug use connection. This may flag an advantage of observing - i.e., being able to see 
the 'big picture' (Hober and Bonnell 2014) without being 'in' the picture (i.e. noticing of significance, but not noticing in context).

\section{Noticing Learning}

While learning is the raison d'être of education, it cannot be assumed that students learn every time they are faced with a learning activity. Boud and Walker (1990) suggest instructors can support learning "by giving a general introduction to the learning situation, and point to particular aspects of it which are particularly relevant to the learning under consideration" (p.73). Activities such as acting in a simulation, or observing a simulation, are no exception. Here we begin with how students were introduced to their roles and what 'particular aspects' were pointed to. The facilitators' lesson plans stated the learning aims were:

To demonstrate the knowledge, skills and application of clinical judgement and decision-making in the care of a patient with respiratory compromise

These aims were not shared with the students. Acting students were provided with a technical briefing (where they could find equipment, limitations of the manikin, etc.). Observing students' briefing typically involved direction on how they should act: '... sit here quietly and watch the simulation on the screen'. Regardless of role (acting or observing), there was little direction on what they would learn as result of the day's activities.

Throughout most of the cycles we observed, observer guides were electronically available to all students prior to attending class. The guides contained a series of questions, or specific features of practice (e.g. clinical actions, team leadership and communication) for observers to 'look out for'. In final four cycles, where the newly developed observer guides were piloted, students were arranged into groups and physically given a copy of the guide along with some instructions about how they should be used. The final question on all guides (see D in Table 1 above) asked students to build on key concepts they had already learned about as well as consider the implications for what they had observed for their (future) practice. In effect, the prompt asks students to notice what they have learned from observing their peers. Below are some responses written by groups responsible for observing communication:

Communicating with the patient is the essential factor in finding out patient's clinical problem.

Listening to the patient - making sure they are comfortable

The burgeoning work on simulation pedagogies typically sees debriefing as the critical component of success. The accepted procedures for debriefing simulation in health and medical education are well documented and replete with references to models of experiential learning (e.g. Lusk and Fater 2013). However, a downside to this is that the debriefing can appear formulaic in nature (Boud and Walker 1990; Nyström et al. 2016). While debriefing sessions provided acting students opportunities to reflect on their learning, overall there were far fewer opportunities for observing students in these sessions. In the first round of data collection the observers' questions were more 
broadly phrased: e.g. "How do you think that went?" which often generated short responses e.g. "Good".

In contrast, acting students were generally invited to reflect on their feelings and experiences, and asked to identify areas for improvement. An example of the later focused on the issue of the illicit drug (Scenario 2) where acting students noticed shortfalls in how they conducted the conversation:

Maybe if the situation wasn't so - what's the word - chaotic. If he was alone with one nurse - one on one, let's talk about this instead of [in front of] everyone in the room.

The facilitator builds on this point by suggesting to the entire class that when students are on upcoming placements they can learn from observing how experienced nurses manage similar conversations: 'Just watch more expert nurses and see how they go about it'. In essence, she advocates for observing with intent to learn - just as Billett (2016) suggests.

\section{Discussion of Case Study}

We began this paper by identifying various forms of professional noticing that need developing in pre-service professionals. In addition to the basic distinguishing of key concepts, we depicted three interrelated forms; noticing in context; noticing of significance; and noticing learning. For those of us charged with preparing learners for professional practice settings we suggest that all three are necessary. Attention to one without the others means it is problematic to act on what is noticed either within a simulation, a classroom activity, or in a professional setting.

Through our illustration of simulation, we saw all three forms of noticing being enacted - although to varying degrees for various groups of students. While students acting in designated roles were confronted through the dynamics of the scenario to notice the situation they were dealing with, and were positioned by the expectations of the scenario to act based on these encounters, they may not have noticed all salient features at the time. Their attention may have been elsewhere, or they did not realise the significance of what they were encountering, or they were unable to act appropriately on this. However, some facilitator interventions prompted these students to notice (e.g. noticing out aloud or narrating noticing). The subsequent debriefing process (noticing learning) also operated to remedy oversights in noticing. Whether it did so successfully or not was due to the ability of the facilitator in engaging students in revisiting the action and seeing what they may have missed or misinterpreted. This is a highly demanding task for the facilitator given limited time and the high level of skill needed to manage the many facets of the debriefing process. 
The observers' role was somewhat different. When the pedagogic design did not involve them sufficiently (e.g. little or no guidance on what or how to notice) observing students were seen to be disengaged. However, the process of deliberately structuring their observations through prompt sheets focused them on noticing more directly. While their attention may have wandered, and been distracted by some of the same dynamics as the actors, they had an external overview of the simulation and the different players, they could notice things that the players could not because of the demands of keeping up with the unfolding action. Nevertheless, observers were caught up in the tension of the situation and followed the hot action (Eraut 1994) of the deteriorating patient - at times more evidently than those playing nursing roles, and especially those playing non-nursing roles. Yet, at the same time there were limits to how much facilitator attention prompted their noticing - indeed, at times the (non)attention may even have diminished what and how they observed. Noticing an event as a player or non-player makes different demands on students. Non-playing observers, if sufficiently involved and attentive, can have a critical distance on the action and while caught up in the drama of the situation can see things that actors cannot. Of course, observation sheets need very careful design. They need to focus attention sufficiently for students to be engaged in careful observation, but not be so overdetermined that students are blind to anything not explicitly prompted.

In concluding our case study we note some prompts and material devices for noticing:

- Observation guides and associated instructions about what to do with them

- Briefing for all on the learning to be had-focusing on what students are supposed to learn.

- Briefing instructions for observers

- Noticing aloud - during the action whether enacted or observed — including facilitator narration

- Debriefing processes, including questioning of players and observers, use of records made contemporaneously, and responses to student comments in the debriefing

We also note some missed opportunities

- Use of observation guides when not tailored to the needs of the observers and noticing learning

- Validation of the importance of observing and helping students form learning intent

- Sufficient time designated to debriefing

- Observers not adequately engaged in debriefing

- Debriefing recipes that do not adequately attend to observers and to observations made.

While these are insights from a study of simulation in nurse education, they may be helpful to consider in the future development of a broader pedagogy of noticing. 


\section{Toward a Pedagogy for Noticing}

The case study presented above draws attention to the difficulties of promoting students noticing in 'real' (albeit simulated) professional settings as well as in coursework activities where students observe episodes of professional practice. Both activities present challenges, and the case study drew insights into some shortfalls that may be addressed with closer attention to pedagogical interventions.

It can be useful to return to Goodwin's (1994) three practices in considering what needs to be emphasised. In our view, the three aspects of noticing discussed here are needed to provide the foundation for the coding, highlighting and articulating material representations that he discusses and move them towards professional practice. Unless the groundwork of noticing has occurred then there is not a solid basis for the other practices he identifies. Noticing does not in itself enable transfer to professional practice: it needs to be embedded in more substantial pedagogies beyond those discussed here. However, transfer of learning can be maximised if learning takes place in the context of transfer (Bowden and Marton 1998). In the case of students learning practices then, noticing is more likely to take place in settings both perceived to be and experienced as authentic.

Any set up, whether real or simulated, will have different affordances, so one of the key challenges for the development of any pedagogy of noticing is to ascertain what these might be. What pedagogical devices are needed to prompt different kinds of noticing? What are appropriate strategies and prompts for noticing required? Our case study points to the importance of close attention to the circumstances in which noticing skills can be developed and the design of a pedagogy that realises the opportunities that the situation provides. It is not sufficient for activities to be set up that require noticing in context and noticing of significance. They need to be carefully designed pedagogically to enable all students to attend to and process things they should be noticing as well as providing an appropriate context through which they can do this. The design also needs to be monitored to determine whether it has the desired effect. Utilising observational devices such as structured observation guides can provide necessary sources of input to noticing for all parties. However, there is also an important need for observations to be interpreted and implications drawn from them. Debriefing mechanisms promote student learning from that which is noticed.

We further suggest that noticing learning itself can be easily overlooked - particularly as substantive subject matter always tends to force itself to centre stage. Exposing pre-service professionals to episodes of practice (whether real or simulated) is not enough, it also requires helping them notice what they will learn, and have learned, from their observations. We tentatively add that a career-long demand for professional learning might also be supported through such measures.

This points to the need for explicit pedagogical design to foster all three forms of noticing. In the present paper we are able to do no more than identify the need for the development of such pedagogies and suggest some of the features they might exhibit. Multiple kinds of learning designs and educator interventions to support learning to notice are necessary. Again, it is not enough to expose students to the complexities of 
practice without also equipping them with tools to guide what they are expected to notice. Such tools need to take into account not only the different foci for noticing but place these in a wider frame of reflective practice that leads to the development of professional vision and framing.

\section{Conclusion}

In this paper, we identified three forms of noticing that need developing in preparing students for practice: noticing in context, noticing of significance and noticing learning and provided an example of how they can be taken up in the context of simulation. We suggested that it is not sufficient for situations to be set up that require noticing in context and noticing of significance. They need to be carefully designed pedagogically to enable students to attend to and process things they should be noticing as well as providing an appropriate context through which they can do this.

The development of noticing necessarily implies a pedagogy in which students are both actively engaged and conscious of their need to monitor their own actions. Noticing needs to be practised and the effects of it reflected upon. It is not developed merely by placing students in authentic or simulated situation. We suggest that many of the outcomes of our study could be readily applied to forms of teaching and learning other than simulation and in contexts other than nursing. Our experience of observing simulation classes leads us to conclude that there are substantial challenges to be faced by educators. It is quite complex to introduce practice-based pedagogy, to do so with the added considerations of developing noticing skills adds to the complexities. We suggest that the pedagogy of noticing be developed further through studies of campusbased courses and how they can not only pursue learning outcomes about the substantive professional subject matter, but perhaps prepare graduates even better for their future careers.

Open Access This article is distributed under the terms of the Creative Commons Attribution 4.0 International License (http://creativecommons.org/licenses/by/4.0/), which permits unrestricted use, distribution, and reproduction in any medium, provided you give appropriate credit to the original author(s) and the source, provide a link to the Creative Commons license, and indicate if changes were made.

\section{References}

Amador, J. (2017). Video simulations to develop preservice mathematics teachers' discourse practices. Technology, Pedagogy and Education. https://doi.org/10.1080/1475939X.2017.1281156.

Barnes, Y., \& Solomon, Y. (2014). Empowering teachers as learners: Continuing professional learning programmes as sites for critical development in pedagogic practices. In C. Day \& J. Sach (Eds.), Workplace learning in teacher education: International practice and policy (pp. 137-150). Dordrecht: Springer.

Barnhart, T., \& van Es, E. (2015). Studying teacher noticing: examining the relationship among pre-service science teachers' ability to attend, analyze and respond to student thinking. Teaching and Teacher Education, 45, 83-93.

Bates, P., \& O'Brien, W. (2013). It's more than stick and rudder skills': an aviation professional development community of practice. Teaching in Higher Education, 18(6), 619-630. https://doi.org/10.1080 /13562517.2013.764862.

Bateson, M. C. (1994). Peripheral visions: Learning along the way. New York: HarperCollins.

Bazerman, M. (2014). The power of noticing: What the best leaders see. New York: Simon \& Schuster.

Billett, S. (2016). Learning through health care work: premises, contributions and practices. Medical Education, 50, 124-131. https://doi.org/10.1111/medu.12848. 
Borich, G. (2016). Observation skills for effective teaching: Research-based practice (7th ed.). New York: Routledge.

Boud, D., \& Walker, D. (1990). Making the most of experience. Studies in Continuing Education, 12 (2),61-80.

Boud, D. \& Rooney, D. (2015). What can higher education learn from the workplace?, in A. Dailey-Herbert \&

K. Dennis (eds), Transformative Perspectives and Processes in Higher Education, Springer, Dordrecht, pp. $195-210$.

Bowden, J., \& Marton, F. (1998). The University of Learning: Beyond quality and competence in higher education. London: Routledge.

Cooper, L., Orrell, J., \& Bowden, M. (2010). Work integrated learning: A guide to effective practice. London: Routledge.

Dossey, L. (2008). Noticing. Explorations, 4(4), 225-227.

Eraut, M. (1994). Developing professional knowledge and competence. London: The Falmer Press.

Fenwick, T., Edwards, R., \& Sawchuck, P. (2011). Emerging approaches to educational research: Tracing the socio-material. Abingdon: Routledge.

Goodwin, C. (1994). Professional vision. American Anthropologist, 96(3), 606-633.

Higgs, J., Barnett, R., Billett, S., Hutchings, M., \& Trede, F. (Eds.). (2012). Practice-based education: Perspectives and strategies. Rotterdam: Sense.

Hober, C., \& Bonnel, W. (2014). Student Perceptions of the observer role in high-fidelity simulation. Clinical Simulation in Nursing, 10(10), 507-514. https://doi.org/10.1016/j.ecns.2014.07.008

Hopwood, N., Rooney, D., Boud, D., \& Kelly, M. (2014). Simulation in Higher Education: A sociomaterial view. Educational Philosophy and Theory, 1-14. https://doi.org/10.1080/00131857.2014.971403

Kelly, M., Hopwood, N., Rooney, D. and Boud, D. (2016). Enhancing students' learning through simulation: dealing with diverse, large cohorts, Clinical Simulation in Nursing, 12, 171-176. https://doi.org/10.1016 j.ecns.2016.01.010

Kutsch, E., \& Hall, M. (2016). Project resilience: The art of noticing, interpreting, preparing, containing and recovering. London: Routledge.

Land, R., Meyer, J. H. F., \& Flanagan, M. T. (Eds.). (2016). Threshold concepts in practice. Rotterdam: Sense.

Lasater, K. (2007). Clinical judgement development: using simulation to create an assessment rubric. Journal of Nursing Education, 46(11), 496-503.

Lucas, U., \& Leng Tan, P. (2014). Developing the reflective practitioner: placement and the ways of knowing of business and accounting undergraduates. Teaching in Higher Education, 19(7), 787-798. https://doi. org/10.1080/13562517.2014.901954.

Lusk, J., \& Fater, K. (2013). Post simulation debriefing to maximize clinical judgement development. Nurse Educator, 38(1), 16-19.

Mason, J. (1993). Learning from experience in mathematics. In D. Boud, R. Cohen, \& D. Walker (Eds.), Using experience for learning (pp. 113-126). Buckingham: Society for Research into Higher Education and Open University Press.

Mason, J. (2002). Researching your own practice: The discipline of noticing. London: RoutledgeFalmer.

Nyström, S., Dahlberg, J., Edelbring, S., Hult, H., \& Abrandt Dahlgren, M. (2016). Debriefing practices in interprofessional simulation with students: a sociomaterial perspective. BMC Medical Education, 16, 148.

Rooney, D., Hopwood, N., Boud, D. and Kelly, M. (2015). The role of simulation in pedagogies of higher education for the health professions: through a practice-based lens, Vocations and Learning: Studies in Vocational and Professional Education, 8,(3)269-285.

Rooney, D. and Kelly, M. (2019). Developing professional noticing: shifting the logic of observer guides from evaluating to noticing (Chapter 6), in Abrandt Dahlgren, M., Felländer Tsai, L., Nyström, S. and Rystedt, H. (eds) Interprofessional Simulation in Health Care: Materiality, Embodiment, Interaction, Springer

Rose, M. (2014). The mind at work: Valuing the intelligence of the American worker (2nd ed.). New York: Penguin Books.

Schön, D. (1983). The reflective practitioner: How professionals think in action. New York: Basic Books Inc.

Smyth, R. (2011). Enhancing learner-learner interaction using video communications in higher education: implications from theorising about a new model. British Journal of Educational Technology, 42(1), 113127.

Stürmer, K., Könings, K. D., \& Seidel, T. (2015). Factors within University-based teacher education relating to preservice teachers' professional vision. Vocations and Learning, 8(1), 35-54.

Tanner, C. (2006). Thinking like a nurse: a researched-based model of clinical judgment in nursing. Journal of Nursing Education, 45(6), 204-211.

Torres, A., Lopez, A., Jorge, M., Valentine, S., \& Mouraz, A. (2017). What catches the eye in observation? Observers perspectives in multidisciplinary peer observation of teaching program. Teaching in Higher Education, 22(7), 822-838. https://doi.org/10.1080/13562517.2017.1301907. 
Watson, F., \& Rebair, A. (2014). The art of noticing: essential nursing practice. British Journal of Nursing, 23(10), 514-517.

Publisher's Note Springer Nature remains neutral with regard to jurisdictional claims in published maps and institutional affiliations.

Dr Donna Rooney is a lecturer/researcher at UTS. The central focus of her research and teaching is adult learning in and beyond educational institutions. She draws from a range of conceptual resources - including, socio-material, post-human, and more recently practice based theories.

Professor David Boud has been involved in research and teaching development in adult, higher and professional education for over 30 years and has contributed extensively to the literature. 